\title{
O traço da origem e o traço do traço: Benjamin e a arqueologia da Spur
}

\section{Alice Mara Serra - UFMG}

Resumo: Este trabalho propõe-se a situar reflexões de Benjamin sobre o traço ou rastro (Spur) no âmbito de uma arqueologia da Spur, pensada a partir de textos de Husserl, Freud e Derrida. Esta se entende sobretudo como analítica quase-transcendental (Derrida) das condições de possibilidade de remissão de vivências de (re)presentificação (fantasia e lembrança) atuais às já decorridas. Arqueologia é entendida aqui menos como reapropriação da origem (arché) daquilo que fenomenologicamente se apresenta e mais como analítica das camadas de sedimentação e dos níveis de disseminação de um objeto ou fragmento de objeto que, ou aparece por si, ou se deixa inferir a partir de outros.

Palavras-chave: traço, origem, arqueologia

Em “Ausgraben und Erinnern” (“Escavar e lembrar", 1932), Walter Benjamin apresenta a figura daquele que visa a aproximar-se de seu passado como a de um arqueólogo que escava: "Quem pretende se aproximar do próprio passado soterrado deve agir como um homem que escava." Já em Passagen-Werk sublinha o autor o fato de que, no traço ou rastro (Spur), apoderamo-nos da coisa: "O rastro (Spur) é a aparição de uma proximidade, por mais longínquo esteja aquilo que o deixou. A aura é a aparição de algo longínquo, por mais próximo esteja aquilo que a evoca. No rastro, apoderamo-nos da coisa; na aura, ela se apodera de nós"2

Ao pensar estas duas passagens em relação, pode-se perguntar se e em que medida, para aquele que visa a aproximar-se de um passado - seja um passado vivenciado e lembrado, seja um passado investigado através de vestígios -, os fragmentos ou restos encontrados teriam caráter de Spur, rastros de outrora que, em sua proximidade ao sujeito, permitiriam a este apoderar-se de um vivido anterior, mesmo que longínquo; ou se os fragmentos remissivos a um suposto passado se manteriam, antes, num distanciamento intransponível, remissivo à distância aurática e à impossibilidade de apropriação.

Antes de examinarmos possíveis respostas a esta questão em textos de Benjamin, vejamos brevemente como o tema da arqueologia da Spur se configura nos pensamentos de Freud, Husserl e Derrida. ${ }^{3}$

A metáfora do arqueólogo que busca reconstruir, a partir de traços e vestígios, um determinado passado, é apresentada por Freud, em analogia com o psicanalista que parte dos fragmentos de lembranças e das associações livres para acessar às supostas origens, aos eventos fundadores dos sintomas ${ }^{4}$, bem como por Husserl, em alusão ao fenomenólogo, que dispõe tão só de momentos ou fragmentos de atos psíquicos atuais para investigar os modos de constituição de atos já decorridos ${ }^{5}$. Estes se encontram, 
segundo a alusão de Husserl à arqueologia, sedimentados, não sendo acessíveis diretamente, mas passíveis de representificação (Vergegenwärtigung). Atos sedimentados podem ser representificados ou quando uma percepção atual os desperta associativamente, ou quando nos dirigimos a eles, no voltar-se da consciência intencional, por exemplo, a uma lembrança específica. ${ }^{6}$ Tal como na estratigrafia arqueológica, um ato sedimentado pode ser analisado, a partir de sua representificação, tanto numa perspectiva cronológico-diacrônica, em relação às camadas de vivências que se sedimentaram antes e depois dele, quanto num sentido sincrônico, segundo suas relações de semelhança e contraste com outros vividos de diferentes épocas. ${ }^{7}$

Mas, ao nos voltarmos a um ato de lembrança ou fantasia, será que podemos nos apropriar, através dele, de uma vivência mais originária? Além disso, será que podemos nos apropriar do próprio vivido atual, em seu despontar repentino como evento consciente, quando este não foi motivado ou intencionado pela instância egoica do psíquico (Freud), instância que, em Husserl, é principalmente assimilada às sínteses ativas (atos de atenção, julgamento e linguagem)?

Por arqueologia do traço entende-se, num primeiro sentido, a remissão de um vivido de representificação atual a uma origem (arché) da qual ele proviera ou a uma totalidade da qual ele teria sido parte, concepção em que o vivido atual tem validade como traço de algo outro, mais originário que ele. Esta perspectiva é presente nas primeiras teorias de Husserl sobre o signo de lembrança, que afirmam o caráter secundário deste em relação à percepção e aos significados ideais constituídos. ${ }^{8}$ Já num segundo direcionamento analítico, desenvolvido a partir de 1918, em Análises sobre a síntese passiva ${ }^{9}$, Husserl destaca a irredutibilidade das vivências de (re)presentificação (atos de fantasia e lembrança) ${ }^{10}$ a sentidos fundadores (perceptivos ou lógicos) bem como a interferência recíproca entre os referidos atos, nos modos como eles se constituem no presente.

Com base na obra de Emil Angern, Die Frage nach dem Ursprung (A questão sobre a origem), pode-se identificar a primeira das abordagens mencionadas como mais voltada para a questão sobre o início do que para a questão sobre a origem: enquanto o "início" (Anfang) corresponde ao primeiro membro de uma série, situando-se como um elemento inicial, exterior aos momentos que lhe seguem, a "origem" (Ursprung) só pode ser pensada retrospectivamente, a partir de e no horizonte daquilo que se tornou. ${ }^{11}$

É como desdobramento deste último sentido que a arqueologia da Spur deixa-se compreender como análise das direções de sedimentação do traço de vivências atuais segundo princípios associativos, mas também dissociativos, e segundo suas modalidades de retorno ou passagem a alguma forma de visibilidade ou poder de afecção. A esta análise segue-se o estudo quase-transcendental das condições de possibilidade de referência do traço a percepções ou vividos não mais presentes. A noção de "quasetranscendental", oriunda de Jacques Derrida, remete a condições de possiblidade que podem ser também condições de impossibilidade ${ }^{12}$. Nesta acepção, há que se levar em conta, como sublinha Derrida em outro contexto, o caráter do traço como "resto" (reste), "restância" (restance) e "resistência" (résistance) ${ }^{13}$ : resto não mais passível de integração a um vivido anterior; restância como permanência da materialidade do traço, independentemente do sentido idealmente constituído; e resistência como possibilidade de não-mostração e de não-integração do traço a teorias interpretativas que procedam ao seu apagamento. Derrida refere-se nisso, em especial, à teoria do traço ou da escritura psíquica formulada por Freud, entendida como camada de sentido mais originária de constituição do psíquico, mas a qual só se deixa pensar em adiamento ou atraso, de forma modificada e parcial, segundo o que se transcreve como fenômeno consciente. ${ }^{14}$ Além 
dos traços que aparecem na consciência e que indicam outros, há aqueles restos que só se deixam assinalar como aquilo que falta numa tentativa de reconstrução.

Vejamos, agora, em que sentidos Benjamin nos ajuda a pensar a arqueologia da Spur, nos sentidos mencionados de remissão a uma origem, de remissão a outros traços e de análise das condições de (im)possibilidade dessas remissões.

No referido texto Ausgraben und Erinnern, compara Benjamin os objetos encontrados em escavações a "imagens que, desprendidas de todas as conexões mais primitivas, ficam como preciosidades nos sóbrios aposentos de nosso entendimento tardio, igual a torsos na galeria do colecionador." ${ }^{15}$ Diante de tais objetos, um arqueólogo ou uma pessoa que se lembra, assim como um colecionador diante dos objetos de sua coleção, poderia "não apenas indicar as camadas das quais originam seus achados, mas também, antes de tudo, aquelas outras que foram atravessadas anteriormente". ${ }^{16}$ Este procedimento estratigráfico - similar àquele acima mencionado - descreve Benjamin mais detalhadamente através da figura do colecionador, em Das Passagen-Werk ${ }^{17}$.

Segundo Benjamin, para um colecionador, em cada objeto de sua coleção está presente não apenas um objeto, mas cada um remete a um passado inteiro e ainda a detalhes de sua história: a seus pré-possuidores, seu valor de origem, seus diferentes significados ao longo do tempo. Para o colecionador - diz Benjamin - esses dados "objetivos" (sachlichen) se reúnem em cada uma de suas posses singulares, formando uma espécie de "enciclopédia mágica, uma ordenação do mundo, cujo compêndio é o destino (das Schicksal) de seu objeto." 18 Na medida em que, para o colecionador, cada um de seus objetos remete a uma ordenação específica, distinta de uma finalidade funcional, ele não estaria diante dos mesmos como um observador indiferente, mas sim, numa atitude similar à do fisionomista atraído pelos objetos que contempla:

[...] os grandes fisionomistas (e colecionadores são fisionomistas do mundo das coisas) tornam-se intérpretes do destino. Basta seguirmos um colecionador que manipula os objetos de sua vitrine. Dificilmente ele os segura em suas mãos, assim ele parece inspirar-se através deles; parece, como um mágico, olhar através deles em sua distância. ${ }^{19}$

O colecionador é aqui apresentado como aquele que, em proximidade a e ao mesmo tempo distância de seus objetos, raramente os toma em suas mãos, embora se deixe inspirar por eles - ou não consegue evitar que isso ocorra. Se o colecionador se abstém de apreender seus objetos, ele não consegue impedir de ser atraído por outros objetos que evoquem, por semelhança, os objetos de sua coleção. Remontando à citação inicial deste texto, há, por um lado, uma aura em torno de cada objeto da coleção, uma aura que os torna pertencentes a um contexto, num lugar singular dentro da coleção. Por outro lado, os objetos exteriores à coleção, ao evocarem ao colecionador os objetos de sua coleção, atuam como traços destes. Assim também, cada objeto da coleção aparece ao colecionador como rastro ou fragmento da própria coleção. Neste caso, eles não seriam, pelo menos para o colecionador, restos ou fragmentos que se extraviem ou que se percam de sua origem. Neste sentido, pode-se considerar que todo colecionador, na expressão de Benjamin, se torne um fisionomista: A partir da aparência assumida por um de seus objetos, ou pelo rastro de um objeto seu, o fisionomista busca investigar seu "destino" até o presente.

Vamos chamar este objeto de 'objeto-fragmento', já que cada objeto singular é, neste caso, ou um fragmento da coleção ou remissão a um objeto da coleção: Diante do objetofragmento, o fisionomista-colecionador investigaria, pois, os significados que se 
precipitaram sobre ele, os deslocamentos pelos quais ele passou. Pensemos, por exemplo, numa coleção de selos: O fisionomista poderia tentar reconstituir, para cada selo, os diversos caminhos percorridos até se tornarem parte de sua coleção: seus possuidores conhecidos e prováveis, suas variações de valor, suas alterações de cor, seus desgastes ou deformações. Ele poderia analisar, por exemplo, as interferências em sua composição, devido ao fato deles terem sido carimbados, ou molhados quando foram extraídos de seu invólucro postal. Lembrando ainda que selos também podem se umedecer, caso o carteiro tenha trazido a correspondência em dia de chuva ou por ter havido orvalho na caixa de correio, condição em que as cores poderiam se alterar pela ferrugem. A análise empreendida pelo colecionador-fisionomista poderia, além disso, prosseguir por várias outras direções, por exemplo, no sentido de tentar retomar a intenção daquele que produziu um objeto-fragmento - neste caso, um selo - numa forma determinada, voltando-se ainda à relação entre este modo de representação e o contexto histórico ao qual ele se referiria (isto pensando ainda em selos, que, geralmente, são - ou eram comemorativos).

Já quando nos voltamos ao traço de (re)presentificação (em atos de lembrança e fantasia) e não mais somente ao objeto físico ao lado de outros, deve-se igualmente considerar outras possíveis deformações e deslocamentos. Se remontarmos a Freud, ele nos diz que o objeto psíquico resiste muito mais que o objeto físico. ${ }^{20}$ Este pode mesmo ser destruído pelos desgastes do tempo e por calamidades naturais. Por exemplo, incêndios, enchentes podem tanto extinguir uma coleção de selos, quanto soterrar ou transformar em cinza casas e cidades. Ali, algum tempo depois, talvez arqueólogos viessem a encontrar traços dos antigos objetos e, ao reunirem diversos fragmentos sobreviventes, tentassem reconstruir uma conjuntura em que eles se situavam. Mas Freud sustenta que, à diferença do objeto físico, do objeto psíquico nada se perde. ${ }^{21}$ Lembremos, todavia, que o mesmo Freud, por um lado, assistia, como analista, aos atos fragmentários de associação livre, à impossibilidade de acessar ao evento originário, suposta origem dos acontecimentos posteriores. Por outro lado, ele assistia também à reprodução - exata, por assim dizer - do nível de intensidade afetiva em que um tal evento teria ocorrido. Freud constata que é isso o que permaneceria intacto na vida psíquica: a intensidade de um evento originário. Os atos psíquicos que se constituem a partir da atualização de um evento originário tendem a se apresentar num nível de intensidade concomitante ao mesmo. Se a energia - o nível quântico - se repete, não há, porém, como impedir que o evento originário se desfigure ou se re-configure segundo seus modos de (re)presentificação atuais. ${ }^{22}$

Com isso, o fisionomista do traço de (re)presentificação terá, sem dúvida, maior dificuldade em reconstituir o seu percurso ou "destino" até o presente, em comparação com o rastreador-fisionomista dos objetos existentes. Isso, sobretudo, porque, se o traço de (re)presentificação remete a outros vividos singulares e a um contexto precedente do qual ele fora parte, ele remete, na verdade, a várias conjunturas anteriores e a vários outros traços singulares, com os quais ele teria estado em relação segundo modalidades diversas: não somente em relações de contiguidade e sucessão e em relações de semelhança e contraste com outros contextos percebidos, mas também em tais relações com situações imaginadas como possíveis e com traços que se perderam.

Suponhamos, por exemplo, que se (re)presentifique para mim num ato de consciência atual uma cadeira que eu teria ganho quando criança. Ao me voltar a esta imagem ou representação, posso afirmar que esta cadeira era, na verdade, um tronco de árvore cerrado por meu avô, meu avô que, às vezes, se fazia de marceneiro. Esta imagem estaria, desta forma, sendo apreendida como signo ou traço remissivo a outras vivências 
de (re)presentificação. Eu poderia reconstruir, a partir deste objeto-traço 'cadeira' ou 'toco de madeira', o contexto original em que eu o teria recebido de meu avô, podendo (re)presentificar, a partir disso, as roupas de meu avô, as pessoas que assistiram a essa tomada de posse, o lugar que eu teria escolhido para colocá-lo. Depois, eu poderia reconstituir o "destino" do banquinho - eu posso vir a dizer que, na verdade, se tratava de um 'banquinho' - de como, depois que ele se tornou pequeno para mim, minha mãe passou a usá-lo como suporte de plantas, e, mais tarde, de como ele foi se umedecendo pelo tempo, alterando sua cor, escurecendo-se em seu centro. Até que, num dado ponto dessa história, eu não mais saberia dizer o que se passou com o banquinho. Eu poderia pensar ter visto um pedaço dele - já que a madeira era da mesma cor e com as mesmas hachuras - servindo de suporte a um outro pedaço de madeira. Mas pode ser também que eu me engane, pode ser que se trate de um outro toco qualquer, sem relação alguma com aquele banquinho-cadeira-tronco-de-árvore, que um dia fora árvore. Mas não vamos mais longe nesta tentativa de reconstrução.

Importa destacar, sobre este tópico, que uma reprodução ou uma tentativa de reconstituição do traço nunca é a mesma, já que podemos nos concentrar, a cada vez, em aspectos diferenciados, passar ao largo de outros. Além disso, outros vividos podem interferir, por si mesmos, no ato de (re)presentificação atual, sem que o possamos evitar. Aí se incluem vividos fantasiados e afetos de dor ou prazer, que podem interromper uma associação em curso. Como assinala Benjamin:

[...] as experiências daquele que segue um traço resultam apenas de modo longínquo de um processo de trabalho ou desatam totalmente deste. Elas não têm nem sequência nem sistema. Elas são um produto do acaso e trazem plenamente em si $[\mathrm{um}]$ inacabamento essencial [...]."23

Se se tratasse de reconduzir, simplesmente, um dado objeto-fragmento ou um traço a seu contexto originário, ou de reconstituir seu possuidor e seu solo originário, a questão seria um tanto mais fácil e se resolveria na primeira associação. Mas, o objeto-fragmento e, mais ainda, o traço de (re)presentificação (em atos de fantasia e lembrança), resistem a que nos apropriemos deles, resistem a que os encaixamos num contexto ou em outro, como bem entendermos. Não que eles não se deixem encaixar, afinal as próprias associações ativas são percursos no "destino" do objeto: São percursos "casuais" que, mais tarde, da perspectiva da tentativa de reconstituição, podem se apresentar como momentos necessários no "destino" do objeto. Todavia, para além dessas direções percorridas nas tentativas de apropriação do traço, há vias que permanecem inacessíveis, que não se deixam reconstituir. Impossível seria, por exemplo, (re)presentificar todos os outros elementos com os quais um traço se relacionasse por semelhança ou contraste. Mas, ao invés de estar preso a nossa própria tentativa de reconstituição, o traço, resto de outros contextos, resta em si, como diria Derrida. Ele pode ter algo a nos dizer, mesmo que se apresente apenas como iminência de assumir uma forma, iminência de evocar algo outro. Nesta potencialidade não de "querer dizer" (vouloir-dire, bedeuten) algo específico, mas de talvez dizer algo ${ }^{24}$ o traço será tanto mais significativo quanto mais ele se apresentar em sua singularidade. Cabe recuperar aqui, acerca deste ponto, uma passagem de Proust citada por Benjamin em Das Passagen-Werk:

[...] um quadro no meio de móveis, cortinas e enfeites da mesma época [...] não nos oferece a mesma alegria inebriante que somente devemos exigir dele numa sala de museu, que simboliza muito melhor, por sua nudez e seu despojamento 
de toda particularidade, os espaços interiores nos quais o artista se abstraiu para criar. $^{25}$

Singularidade não significa, aqui, recuperar o caráter único ou aurático da obra única, do fragmento único, mas singularidade remete, neste âmbito, ao hiato ou disjunção de um objeto-fragmento ou de um traço em relação a um suposto contexto originário. A própria atitude histórico-materialista se assimilaria, para Benjamin, a este procedimento, ao não escolher e nem "apreender" (sie greift nicht) seus objetos, mas ao "desprendê-los" (sprengt heraus) do curso em que foram inseridos. ${ }^{26}$ Desta disjunção originária amplia-se a capacidade de remissão de um traço ou objeto-fragmento a outros contextos. Como formula Benjamin, "para que um pedaço do passado seja encontrado pela atualidade, não deve existir uma continuidade entre eles." ${ }^{27}$ Ainda neste contexto de sentido, Benjamin nos lembra, ao descrever uma foto de Kafka, que os olhos tristes deste - exatamente por destoarem do ambiente aveludado e dos trajes ornamentais de fotografia que o pequeno Kafka fora obrigado a vestir - teriam algo a nos dizer sobre aquele contexto e além dele.

Em sua tristeza, esse retrato contrasta com as primeiras fotografias, em que os homens ainda não lançavam ao mundo, como o jovem Kafka, um olhar desolado e perdido. Havia uma aura em torno deles, um meio que atravessado por seu olhar lhes dava uma sensação de plenitude e segurança. Mais uma vez existe para isso um equivalente técnico: o continuum absoluto da luz mais clara à sombra mais escura. ${ }^{28}$

Enquanto os olhos tristes de Kafka des-auratizam o mundo ao se chocarem com ele, o continuum em que claro e escuro passam gradativamente um ao outro sem se chocarem traduz um artifício dos velhos retratistas para manter a aura na fotografia: $\mathrm{O}$ mezzo-tinto, o esfumaço com que o retratista envolvia a imagem humana, permitia a esta destacar-se do fundo, ao mesmo tempo em que iludia diluir seus limites com o ambiente. ${ }^{29}$ Como se pode ver em "Sobre o conceito da História" (Über den Begriff der Geschichte), esse artifício é similar ao do historiador em torno dos grandes feitos: a aura em torno destes faz da história uma sucessão de triunfos, uma harmonia causal que dilui as incongruências. ${ }^{30}$ Em contrapartida a esse artifício dos "velhos retratistas" ou dos "velhos historiadores', as fotografias de Eugène Atget ("Pequena História da Fotografia": Kleine Geschichte der Photographie) seriam emancipadoras no sentido dele conseguir, por intermédio da câmera, captar um mundo sem aura e aproximá-lo do espectador, produzindo, neste, um estranhamento que o poderia levar a um reconhecimento de outro tipo.

Quase sempre Atget passou ao largo das "grandes vistas e lugares característicos", mas não negligenciou uma grande fila de fôrmas de sapateiro, nem os pátios de Paris, onde da manhã a noite se enfileiram carrinhos de mão, nem as mesas com os pratos sujos ainda não retirados, como existem aos milhares, na mesma hora $\left[\ldots . .{ }^{31}\right.$

À diferença do procedimento dos velhos retratistas, acima mencionado, Atget retratava restos, ruas desertas, fachadas partidas, lugares abandonados, séries de objetos estilhaçados. Reproduzidos em fotos que, por sua vez, poderiam ser expostas, às dezenas, nos mesmos lugarejos sem aura, essas imagens provocam um estranhamento naquele que as contempla: o rosto humano é ausente, não há um lugar único em que se reconheça. 
Uma massa de homens desterrados talvez pudesse se reconhecer nestas fotos. Mas talvez também um olhar único.

Por um lado, quanto mais desprovido de aura, do esfumaço que o religa a um contexto único, mais o traço, ou o objeto-fragmento, assume seu potencial de remeter à origem: Lembrando que a origem não se confunde com o início, o ponto inicial em que algo veio a ser, mas a origem é falta originária a si, que, como assinala Derrida, demanda um suplemento de existência, um deslocamento, uma remissão a outros possíveis, não mais ou não ainda presentes. ${ }^{32}$ Isso é também o que ocorre, como se pode ver a partir de Benjamin, naquilo que nos olhos na imagem de Kafka e nos textos de Kafka excede ou não se harmoniza com o contexto em que se situavam. As coisas no mundo de Kafka, segundo Benjamin, ou eram anteriores demais a seu tempo ou velhas demais para ele: "[...] coisas que não chegaram a ser e [...] coisas que amadureceram demais". ${ }^{33}$ Não se sabe, diz Benjamin, como Kafka foi capaz de suportar isso.

É nesse hiato, nessa temporalidade dissimétrica que temos também o lugar do traço e, em menor grau, do objeto-fragmento: Podendo recuar diante da tentativa de apropriação no momento em que lhe dirigimos, ele pode se nos apresentar, num momento posterior, como elucidador de si, de seu enigma, de seu "destino", ou ainda de um mundo dentro do mundo, sem que esperássemos por essa revelação. Se isso ocorrer, o traço nos aparece, por assim dizer, com um teor aurático, como a aparição de algo distante, por mais próxima que esteja de nós a sua aparição. Não podemos nos apropriar dele, mas, no momento em que, por mais que o quiséssemos, não conseguíssemos nos desviar dele, é ele que se apropriaria de nós. Neste caso, a reprodutibilidade do traço, porque nunca o reproduz como o mesmo, porque nunca reproduz o evento (Ereignis), não efetiva uma perda de sua aura.

Há, pois, que pensar aura e traço não como duas polaridades, mas em sua distância e proximidade desviantes, em seus graus de intensidade divergentes: nos modos em que nos aproximarmos e nos distanciarmos disso que se indica e indica outros, e nos modos em que isso se aproxima ou se distancia de nós. Da proximidade em que supomos apreender seu "destino", podemos averiguar como isso nos escapa. Por sua vez, da distância em que, por vezes, o traço-evento nos chega, sem lhe estarmos voltados ou sem o intencionarmos, ele pode se apresentar em proximidade-distância, a meio-caminho entre o fragmentário de traço e o teor aurático originário: Aparição e revelação singular, infinitamente distante, porque não passível de apropriação; infinitamente outro e remissão a outros, porque não redutível aos sentidos e percursos que, porventura, viermos a lhe atribuir.

Abstract: This study intends to place Benjamin's reflections on the trace (Spur) into the context of a Spur's archeology, thought Husserl's, Freud's and Derrida's works into consideration. This study primarily aims at a quasitranscendental analysis (Derrida) that concerns the conditions under which the remission of current experiences dealing with (re)presentification (fantasy and memory) to previous ones is possible. In this approach, archaeology is seen less as a reappropriation of origin (arché) of what presents itself phenomenologically, but rather as an analysis of the strata of sedimentation and the levels of dissemination of an object or piece of an object that appears by itself or that can be inferred to from others. 
Keywords: trace, origin, archaeology

\section{Referências Bibliográficas}

ANGEHRN, Emil. Die Frage nach dem Ursprung: Philosophie zwischen Ursprungsdenken und Ursprungskritik. München: Wilhelm Fink, 2007.

BENJAMIN, Walter. Pequena história da fotografia (1931). In: BENJAMIN, Walter. Magia e técnica, arte e política: ensaios sobre literatura e história da cultura. 7. ed., trad. Sérgio Paulo Rouanet. São Paulo: Brasiliense, 1994, p. 91-107. - (Obras escolhidas; v. $1)$.

Ausgraben und Erinnern (1932). Gesammelte Schriften IV/1: Kleine Prosa/ Baudelaire Übertragungen. Frankfurt: Suhrkamp, 1972, p. 400-401.

Escavando e lembrando. In: BENJAMIN, Walter. Rua de Mão única. 5. ed., trad. Rubens Rodrigues Torres Filho e José Carlos Martins Barbosa. São Paulo: Brasiliense, p. 239-240 - (Obras escolhidas; v. 2).

Franz Kafka: a propósito do décimo aniversário de sua morte (1934). In: BENJAMIN, Walter. Magia e técnica, arte e política: ensaios sobre literatura e história da cultura. 7. ed., trad. Sérgio Paulo Rouanet. São Paulo: Brasiliense, 1994, p. 137-164 (Obras escolhidas; v. 1).

Sobre o conceito da história (1940). In: BENJAMIN, Walter. Magia e técnica, arte e política: ensaios sobre literatura e história da cultura. 7. ed., trad. Sérgio Paulo Rouanet. São Paulo: Brasiliense, 1994, p. 222-232. - (Obras escolhidas; v. 1).

Das Passagen-Werk. 1. ed. Editado por Rolf Tiedemann. Erster Band. Frankfurt: Suhrkamp, 1983.

Das Passagen-Werk. 1. ed. Editado por Rolf Tiedemann. Zweiter Band. Frankfurt: Suhrkamp, 1983.

DERRIDA, Jacques. La voix et le phénomène: Introduction au problème du signe dans la phénoménologie de Husserl. Paris: PUF, 1967.

Freud et la scéne de l'écriture. In: DERRIDA, Jacques. L'écriture et la différence. (Reimpressão da edição de 1967). Paris: Éd. du Seuil, 2006, p. 293-340.

Signature événement contexte. In: DERRIDA, Jacques. Marges de la Philosophie.

Paris: De Minuit, 1972, p. 365-393.

Résistances. In: DERRIDA, Jacques. Résistances de la psychanalyse. Paris: Galilée, 1996, p. 11-53.

(1997). Une certaine possibilité impossible de dire l'événement. In: DERRIDA.

Dire l'événement, est-ce possible? Paris: L'Harmattan, 2001, p. 81-112.

GÜNZEL, Stephan. Zick-Zack: Edmund Husserls phänomenologische Archäologie. In: ALTEKAMP, Stefan e EBELING, Knut (org.). Die Aktualität des Archäologischen: Kulturwissenschaften, Medien, Künste. Frankfurt: Fischer, 2004, p. 98-117.

FREUD, Sigmund. Briefe an Wilhelm Fließ 1887-1904. Editado por J. M. Masson. Frankfurt: Fischer, 1986. 
Entwurf einer Psychologie (1895). GW Nachtragsband: Texte aus den Jahren 1885-1938. Frankfurt: Fischer, 1987, p. 373-486.

Zur Psychotherapie der Hysterie (1893). In: FREUD, Sigmund. Studien über Hysterie. GW I: Werke aus den Jahren 1892-1899. 5. ed. Frankfurt: Fischer, 1977, p. 252-312.

Notiz über den "Wunderblock" (1925 [1924]). Studienausgabe III: Psychologie des Unbewussten. Frankfurt: Fischer, 2000, p. 363-369.

Das Unbehagen in der Kultur (1930). GW XIV: Werke aus den Jahren 1925-1931. 4. ed. Frankfurt: Fischer, 1968, p. 419-506.

Konstruktionen in der Analyse (1937). GW XVI: Werke aus den Jahren 19321939. 2. ed. Frankfurt: Fischer, 1961, p. 41-56.

HOCK, Udo. Die Zeit des Erinnerns. Psyche: Zeitschrift für Psychoanalyse und ihre Anwendungen 57, 9/10 (2003), p. 812-840.

HUSSERL, Edmund. Texte zur Phänomenologie des inneren Zeitbewusstseins (18931917). Text nach Hua Bd. X. Editado por R. Bernet. Hamburg, Felix Meiner, 1985.

Hua XI: Analysen zur passiven Synthesis. Aus Vorlesungs- und Forschungsmanuskripten 1918-1926. Editado por M. Fleischer. Den Haag: Martinus Nijhoff, 1966.

Hua XIX/1: Logische Untersuchungen: Untersuchungen zur Phänomenologie und Theorie der Erkenntnis. Editado por U. Panzer. The Hague: Martinus Nijhoff, 1984.

Materialien VIII (Mat. VIII): Späte Texte über Zeitkonstitution (1929-1934): Die C-Manuskripte. Editado por D. Lohmar. Dordrecht: Springer, 2006.

LACAN, Jacques. Le séminaire VII: L'éthique de la psychanalyse, 1959-1960. Texte établi par J.-A. Miller. Paris: Du Seuil, 1986.

MARUCCO, Noberto C. Zwischen Erinnerung und Schicksal: die Wiederholung. Psyche: Zeitschrift für Psychoanalyse und ihre Anwendungen 61 (2007), p. 322-344.

SERRA, Alice M. Archäologie des (Un)bewussten: Freuds frühe Untersuchung der Erinnerungsschichtung und Husserls Phänomenologie des Unbewussten. Würzburg: Ergon, 2010.

Sedimentierung. In: GANDER, Hans-Helmuth. Husserl-Lexikon. WGB: Darmstadt, 2010, p. 263-264.

\section{Notas}

1 "Wer sich der eigenen verschütteten Vergangenheit zu nähern trachtet, muss sich verhalten wie ein Mann, der gräbt." (BENJAMIN. Ausgraben und Erinnern (1932), p. 400 / Escavando e recordando, p. 239).

2 "Spur und Aura. Die Spur ist die Erscheinung einer Nähe, so fern das sein mag, was sie hinterließ. Die Aura ist die Erscheinung einer Ferne, so nah das sein mag, was sie hervorruft. In der Spur werden wir der Sache habhaft; in der Aura bemächtigt sie sich unser." (BENJAMIN. Das Passagen-Werk, M 16 a, 4, p. 560).

${ }^{3}$ Para uma visão mais detalhada, ver: SERRA. Archäologie des (Un)bewussten.

${ }^{4}$ A metáfora arqueológica emerge no incipiente pensamento de Freud, no contexto de seus estudos sobre a histeria, onde o autor procura descrever as camadas e disposição psíquica de lembranças, quando estas não mais se encontram no modo da consciência 
atual (ver: FREUD. Zur Psychotherapie der Hysterie, p. 291 et seq.). Posteriormente, o tema da arqueologia é retomado em diversos textos de Freud, sejam voltados ao método analítico, sejam a estudos culturais (ver: FREUD. Konstruktionen in der Analyse, p. 45 et seq.; FREUD. Das Unbehagen in der Kultur, p. 428 et seq.).

5 Husserl trata especificamente do paradigma arqueológico num manuscrito tardio, posteriormente publicado nos "Textos tardios sobre a constituição do tempo" (HUSSERL. Späte Texte über das Zeitbewusstsein (Mat. VIII), C 16, Nr. 80, p. 356 et seq.). O manuscrito foi também publicado junto a: GÜNZEL. Zick-Zack: Edmund Husserls phänomenologische Archäologie, p. 98-117.

${ }^{6}$ Ver: HUSSERL. Hua XI: Analysen zur passiven Synthesis. Aus Vorlesungs- und Forschungsmanuskripten 1918-1926; SERRA. Sedimentierung. In: GANDER, HansHelmuth. Husserl-Lexikon, p. 263-264.

7 Esta dupla estruturação, que denominei de 'eixo sincrônico' e 'eixo diacrônico' da sedimentação, remete, além da obra de Husserl acima referida, à "Carta 52" de Freud a Fließ (FREUD. Freuds Brief an Fließ vom 6.12.1896 - Brief 112 [52], in: FREUD. Briefe an Wilhelm Fließ, p. 217-219). Ver: SERRA. Archäologie des (Un)bewussten, p. 146-174; cf. LACAN. Le Seminaire VII, p. 80.

${ }^{8}$ HUSSERL. Hua XIX/1: Logische Untersuchungen, p. 31 et seq. Cf. HUSSERL. Texte zur Phänomenologie des inneren Zeitbewusstseins, p. 158 et seq.

9 HUSSERL. Hua XI: Analysen zur passiven Synthesis. Aus Vorlesungs- und Forschungsmanuskripten 1918-1926; ver, em especial: Vorlesung 3.

10 A notação de (re)presentificação (Vergegenwärtigung) com o prefixo re entre parênteses explica-se no sentido de que Husserl inclui os atos de lembrança e fantasia na mesma classe de atos de consciência da imagem (Bidbewusstsein) e ao mesmo tempo os distingue respectivamente como atos de posicionalidade (Positionalität) e atos de neutralidade (Neutralität). Enquanto a percepção é classificada como ato de presentificação (Gegenwärtigung) simples, a fantasia e a lembrança teriam a peculiaridade de remeter a uma outra vivência ou de trazer de volta à consciência uma vivência anterior. Todavia, enquanto a lembrança tem o caráter de posicionalidade, devido à possibilidade de inferir a partir da vivência atual a existência de um determinado passado, na fantasia esta inferência é inexistente, o que lhe confere uma posição intermediária entre a percepção presentificante e a lembrança representificante.

11 "Der Anfang ist ein Erstes, von dem etwas ausgeht, mit dem etwas beginnt; der Ursprung ist ein Erstes, zu dem wir zurückgehen, das Späterem voraus- und zugrunde liegt. Der Anfang ist prospektiv, als Initialpunkt des von ihm Gesetzten oder aus ihm Entstehenden, der Ursprung retrospektiv, als Grund und Herkunft des Gewordenen bestimmt." (ANGEHRN. Die Frage nach dem Ursprung, p. 23).

12 Ver: DERRIDA. Une certaine possibilité impossible de dire l'événement, p. 86 et seq.

${ }^{13}$ DERRIDA. Résistances, p. 44 et seq.

${ }^{14}$ DERRIDA. Freud et la scéne de l'écriture, p. 306 et seq. A teoria da "arqui-escritura" (archi-écriture) de Derrida remete principalmente aos seguintes textos de Freud: Brief 112 [52], in: FREUD. Briefe an Wilhelm Fließ, p. 217-219; Entwurf einer Psychologie; Notiz über den Wünderblock.

${ }^{15}$ BENJAMIN. Escavando e lembrando, p. 239.

${ }^{16}$ BENJAMIN. Escavando e lembrando, p. 240.

${ }^{17}$ BENJAMIN. Das Passagen-Werk, O ${ }^{0}, 6$ (Zur Gestalt des Sammlers) et seq., p. 1027.

${ }^{18}$ BENJAMIN. Das Passagen-Werk, O ${ }^{0}, 7$, p. 1027.

${ }^{19}$ BENJAMIN. Das Passagem-Werk, $\mathrm{O}^{0}, 7$, p. 1027.

${ }^{20}$ FREUD. Konstruktionen in der Analyse, p. 46.

${ }^{21}$ FREUD. Konstruktionen in der Analyse, p. 46.

22 Ver, por exemplo: MARUCCO. Zwischen Erinnerung und Schicksal: die Wiederholung, p. 322-344; HOCK. Die Zeit des Erinnerns, p. 823. 
3 BENJAMIN. Das Passagen-Werk, m 2, I, p. 963.

${ }^{24} \mathrm{Cf}$. DERRIDA. La voix et le phénomène, p. 17 et seq.

${ }^{25}$ BENJAMIN. Das Passagen-Werk, S 11, I, p. 697.

26 "Die materialistische Geschichte wählt ihre Gegenstände nicht leichter Hand. Sie greift nicht, sondern sprengt sie aus dem Verlauf heraus." (BENJAMIN. Das Passagen-Werk, N 10 a, I, p. 594).

27 "Damit ein Stück Vergangenheit von der Aktualität betroffen werde, darf keine Kontinuität zwischen ihnen bestehen." (BENJAMIN. Das Passagen-Werk, N 7, 7, p. 587).

${ }^{28}$ BENJAMIN. Pequena história da fotografia, p. 98.

${ }^{29}$ BENJAMIN. Pequena história da fotografia, p. 98 et seq.

${ }^{30}$ BENJAMIN. Sobre o conceito de história, p. 222 et seq.

${ }^{31}$ BENJAMIN. Pequena história da fotografia, p. 101.

${ }^{32}$ Ver, por exemplo: DERRIDA. Signature événement contexte, p. 365-393.

${ }^{33}$ BENJAMIN. Franz Kafka: a propósito do décimo aniversário de sua morte, p. 152. 